\title{
PERSONAS: A TEORIA JUNGUIANA DOS TIPOS PSICOLÓGICOS E SUA UTILIDADE PARA O DESIGN
}

\author{
Personas: the jung's theory of psychological types and their utility for design \\ SENNA, Carlos Eduardo \\ Universidade Federal do Rio Grande do Sul | UFRGS \\ carlossenna@hotmail.com
}

\author{
FIALHO, Francisco Antônio \\ Universidade Federal de Santa Catarina | UFSC \\ fapfialho@gmail.com>
}

\section{Resumo}

O presente artigo oferece um novo olhar no processo de construção de personagens, pautado nos ensinamentos da psicologia arquetípica. Para isso, a estratégia metodológica adotada foi a revisão bibliográfica. Inicialmente, o texto mostra os princípios da Teoria dos Tipos Psicológicos, a face mais conhecida da Psicologia Analítica, de Carl Jung. Em seguida, o artigo descreve a classificação tipológica de Myers-Briggs. Um dos maiores desafios para o designer é definir dados psicográficos de um público. Nesse sentido, a teoria junguiana pode ser aproveitada para definição de necessidades coletivas.

Palavras chave: Persona. Psicologia arquetípica. Teoria dos tipos psicológicos. Necessidades coletivas.

\section{Abstract}

This article provides a new perspective for the process of character construction through the knowledge of archetypical psychology. In order to do so, the methodological strategy used was the bibliographic review. Firstly, the text presents the principles of the Psychological Types Theory, the most known branch of Analytical Psychology by Carl Jung. Secondly, the article describes the typological classification of Myers-Briggs. One of the biggest challenges for the designer is to define psychographic data of a specific audience. In this sense, Jung's theory contributes to the definition of collective needs.

Keywords: Persona. Archetypal psychology. Theory of psychological types. Collective needs. 


\section{INTRODUCÃO}

Atualmente, existem diferentes técnicas que permitem a aproximação do usuário no processo de desenvolvimento de um produto e, portanto, propiciam qualidade ao objeto final. A maioria dessas técnicas tem sua origem na investigação social e na análise do comportamento humano. Derivam de áreas como Antropologia, Sociologia, Psicologia e Marketing.

A definição do público-alvo, por exemplo, é encarada como um elemento primordial no Design. É tão importante que não pode ser feita por meio de uma simples descrição técnica (PAZMINO, 2015). É uma atividade intensa, que exige amplo conhecimento de interesses, preferências e habilidades do sujeito. Em muitos casos, para realizar essa definição, o designer faz uso de personagens que simulam condições reais do indivíduo, descrevendo-os de forma a representar uma parcela da população. Esses personagens (conhecidos como personas), são criados visando a redução de riscos para o projeto.

Definir personas não é uma tarefa simples. Não pode ser feita de forma intuitiva, com base em "suposições". Para ser útil ao projeto, o profissional deve se basear em dados efetivos, concebidos a partir de sínteses de comportamentos. Apesar de a literatura consultada deixar claro que as personas devem ser criadas desta forma (com base nos comportamentos reais dos indivíduos), diferentes exemplos são trazidos nos meios acadêmico e profissional com descrições superficiais para os sujeitos. Este agravante é evidenciado por Cybis, Betiol e Faust (2010), quando observam que as criações nem sempre são baseadas em informações qualitativas. Os autores indicam que, em muitos casos, as personas são criadas, apenas, com base em dados demográficos.

Sendo assim, a questão básica que norteia esta pesquisa pode ser expressa da seguinte forma: Como podem ser adquiridos dados psicográficos e comportamentais de um público para auxílio nos projetos de Design? O presente artigo sugere que seja utilizada a Teoria dos Tipos Psicológicos de Carl Jung (2000). Em conjunto com a teoria, o estudo propõe que seja consultada a classificação tipológica de Myers-Briggs, já aproveitada em outras áreas de conhecimento. A classificação de Myers-Briggs é amplamente discutida em diferentes campos, podendo ser aproveitada, do mesmo modo, no Design.

Como resultado, a presente pesquisa propõe a correlação entre a teoria junguiana e a técnica de construção de personagens. Acredita-se que esta correlação existe e é imprescindível para o Design, podendo ser utilizada na compreensão de necessidades coletivas, bem como no entendimento de temperamentos do consumidor.

Vale lembrar que como estratégia metodológica foi adotada a revisão bibliográfica narrativa, pois não foram utilizados critérios explícitos e 
sistemáticos de condução. O texto possui um propósito mais amplo, ao estabelecer relações com produções anteriores e apontar novas perspectivas de condução da técnica.

\title{
2. A PSICOLOGIA ANALITICA DE JUNG
}

Por muitos anos, o psicólogo e psiquiatra suíço Carl Gustav Jung (18751961), perseguiu a ideia de criar uma psicologia geral, que mapeasse a psique em suas múltiplas dimensões. Oficialmente, o termo "Psicologia Analítica" só foi utilizado por Jung em 1913 (STEIN, 1998). Mesmo assim, suas bases teóricas foram geradas anos anteriores, à medida que o autor ia descobrindo as camadas impessoais do inconsciente'.

A obra de Jung está intimamente interligada com os acontecimentos de sua vida, assim como nos estudos clínicos realizados em seus pacientes. Como descreve Stein (1998, p. 88), “a experiência de Jung com pacientes neuróticos encorajou-o a pensar que existe, dentro do inconsciente, importantes elementos formadores". Estes elementos formadores fundamentaram duas instâncias da psique, descritas da seguinte forma:

\begin{abstract}
Uma camada mais ou menos superficial do inconsciente é indubitavelmente pessoal. Nós a denominamos inconsciente pessoal. Este, porém, repousa sobre uma camada mais profunda, que já não tem sua origem em experiências ou aquisições pessoais, sendo inata. Esta camada mais profunda é o que chamamos inconsciente coletivo. Eu optei pelo termo "coletivo" pelo fato de o inconsciente não ser de natureza individual, mas universal [...] (JUNG, 2000, p. 15).
\end{abstract}

Desse modo, subsequente à psique do inconsciente pessoal, está o inconsciente coletivo, que é estruturado por padrões. Estes foram identificados em diferentes pessoas, independentemente do fator cultural, religioso ou ético. A princípio, o conceito "inconsciente" limitava-se a designar o estado dos conteúdos reprimidos (JUNG, 2000). No caso do inconsciente coletivo, estes conteúdos foram, mais tarde, denominados de arquétipos.

1 A ideia filosófica de inconsciente não prosperou em um primeiro momento, em virtude do empirismo presente na Europa nos séculos XVII e XVIII. Em seu livro, os arquétipos e o inconsciente coletivo, Jung descreve que o conceito de inconsciente foi aceito paulatinamente, ganhando força, a princípio, no âmbito da psicologia médica, orientada pelas ciências naturais (JUNG, 2000). 


\subsection{A Noção de Arquétipo}

O termo arquétipo, de acordo com Stein (1998), foi inicialmente utilizado por Jung no começo do século XX, entre os anos de 1909 e 1912. A expressão já era conhecida na Antiguidade e fazia referência às representações do inconsciente. Ramos (2002), depois de recorrer ao mesmo autor, também comenta sobre os arquétipos, alegando que são "núcleos instintivos". Isto significa dizer que a gênese do inconsciente coletivo é, portanto, a priori ao nascimento, pois os padrões de comportamento são herdados pela humanidade desde seu surgimento.

Os padrões de comportamento, citados no parágrafo anterior, foram constatados por Jung assim que ele reuniu uma série de mitos, contos de fadas e motivos religiosos, oriundos de remotas paragens pelo mundo. Stein (1998) relata que, depois de interpretar tais imagens, Jung ficou impressionado com as afinidades existentes entre temas da mitologia egípcia, de tribos aborígenes da Austrália e de povos nativos Americanos. Eram civilizações que, aparentemente, não tiveram contato entre si, e viveram em períodos históricos distintos. Apesar disso, tinham características em comum, de pensamento e de imaginação.

De posse dessas constatações, Jung (2000) descreve, então, o conceito de "arquétipo" como sendo algo que nos ocupa. Para o autor, a denominação é precisa e de grande valia, pois diz que, no concernente aos conteúdos do inconsciente coletivo, são tratados tipos primordiais de imagens universais, que existem desde os tempos mais remotos (JUNG, 2000). Nesse sentido, é oportuno dizer que existiram (e ainda existem) imagens que aparecem com maior frequência na psique humana. É o caso do arquétipo do herói, da mãe geradora, do sábio, do vilão, etc.. São imagens permanentes e importantes, encontradas em diferentes civilizações.

Como se pode observar, o significado do termo "arquétipo" torna-se compreensível quando está relacionado com o mito, com o ensinamento esotérico ou com narrativas de caráter simbólico-imagéticas. Porém, o assunto é mais complexo quando fundamentado psicologicamente (JUNG, 2000). Neste caso, Fialho e Fernandes (2014) decidiram apresentar os ensinamentos de Jung com o caráter hermenêutico. Tais ensinamentos, depois de compreendidos, direcionaram os estudos para o campo do Design.

\subsection{A Teoria dos Tipos Psicológicos}

No ano de 1921, Jung publicou um importante livro, denominado "Tipos Psicológicos". Nele, o autor buscou traçar diferentes tipologias humanas, a partir do entendimento intrínseco da psique. Com base nas observações diárias de seus pacientes, assim como no exercício da Medicina Psiquiátrica, Jung definiu os tipos psicológicos. Para isso, ele propôs, inicialmente, dois modos de adaptação 
do homem. Essa subdivisão recebeu o nome de disposições (que equivale às atitudes humanas). Em seguida, Jung achou necessário trabalhar as funções psíquicas (dando o nome de racionais e irracionais) ${ }^{2}$. A visão geral dos tipos psicológicos é indicada a seguir (figura 1).

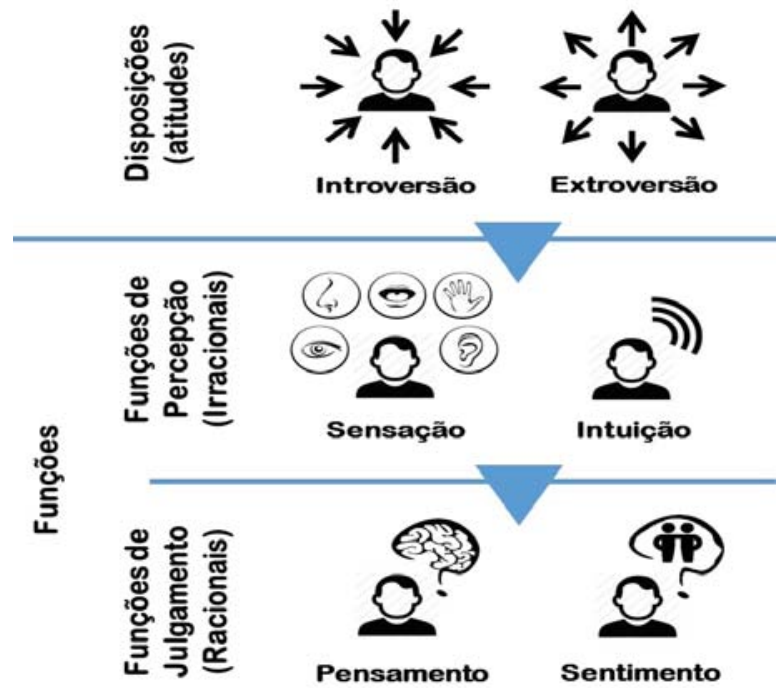

Fonte: Elaborado pelos autores (2016)

Como pode ser observado na imagem, a primeira subdivisão foi especificada em dois tipos: Extroversão ou Introversão.

O introvertido comporta-se da maneira adequada à abstração. No fundo, está sempre disposto a privar o objeto de libido, como se tivesse de evitar e impedir a preponderância do objeto. O extrovertido, pelo contrário, comporta-se positivamente em face do objeto. Afirma a sua significação em tal medida que orientará sua propensão subjetiva no sentido do objeto e relacioná-la-á consigo próprio, de um modo constante (JUNG, 1991, p. 386).

Em outras palavras, a primeira partição sugere a maneira na qual as pessoas interagem com o mundo, ou seja, como lidam e orientam sua libido tarde, os termos percepção e julgamento foram dados por Isabel Myers e Katharine Briggs. 
(energia vital) ${ }^{3}$. Existem pessoas que direcionam suas energias para situações de convívio interno (introvertidas). Em geral, são indivíduos introspectivos, reservados e pensativos, que se sentem "energizados" com atividades reflexivas. Por outro lado, existem pessoas que, naturalmente, orientam sua libido para o mundo externo (extrovertidas). Estas, já são mais "abertas", discursistas, pois concentram seu tempo em atividades coletivas.

Os dois tipos de disposição são completamente distintos e estão presentes em todas as pessoas, em maior ou menor grau. Para explicar melhor a primeira subdivisão de Jung, Ramos (2002) deixa claro que não existe um sujeito totalmente extrovertido ou totalmente introvertido. De fato, o que determina a disposição é o fluxo de libido, que faz predominar o padrão comportamental no indivíduo.

\begin{abstract}
Em termos de fluxo de libido, o consciente e o inconsciente apresentam características opostas, porém, complementares. Se no plano consciente predomina um determinado tipo de disposição, no plano inconsciente o que se verá é a preponderância da disposição contrária e complementar à do consciente. Trata-se de um aspecto de "compensação" próprio da psique (um mecanismo psicofisiologicamente herdado) que tem como objetivo a adaptação do indivíduo ao seio meio. Embora uma disposição predomine sobre a outra, as duas estão presentes no sujeito, o que the possibilita adaptar-se às exigências postas por seu mundo interior (a realidade subjetiva, psíquica) e por seu mundo exterior (a realidade objetiva, ambiental e social). (RAMOS, 2002, p. 137).
\end{abstract}

Depois de entender as duas disposições/atitudes principais, o estudo seguiu com a compreensão das funções psíquicas (de pensamento, de sentimento, de sensação e de intuição). No decorrer de seu livro, Jung (2000) percebeu que não existem somente pessoas introvertidas ou extrovertidas. Além de possuir as duas disposições indicadas, o indivíduo também é guiado por pensamentos. Nesse sentido, partiu-se para a descrição da segunda subdivisão, que diz respeito à forma como as pessoas assimilam as informações do dia a dia. Na função "Percepção", as pessoas também podem ser classificadas de duas maneiras (por Sensação ou por Intuição).

3 Ramos (2002) associa o conceito de libido com a ideia de energia vital. Isso inclui não apenas a sexualidade, mas, também, outros elementos, tais como: os instintos de sobrevivência (sede, fome, agressividade, necessidade de proteção física, etc.), a busca de relações afetivas, a busca de relações sociais, a busca de autoconhecimento, etc.. 
Como o próprio nome sugere, Sensação é um processo pelo qual um estímulo provoca uma reação direta no indivíduo, por meio da visão, do tato, da audição, do paladar e/ou do olfato. As pessoas classificadas nessa condição, recebem estímulos imediatos e depois os julgam. Isso ocorre porque a consciência está voltada ao concreto, sendo guiada, principalmente, pelos 5 sentidos. Existem pessoas que se identificam com esse perfil e lidam com os detalhes de forma bem perspicaz.

Já, no caso da Intuição, as pessoas são tomadas por imagens e acabam assimilando informações a partir de conexões. As conexões ocorrem espontaneamente, por pressentimentos e inspirações. Pessoas do tipo "intuição" tendem a focar no todo ao invés das partes, e, por isso, costumam apresentar dificuldades na compreensão de detalhes. Por outro lado, são pessoas intensamente criativas (inovadoras), que conduzem o pensamento por analogias, sem ter o raciocínio linear. Fialho e Fernandes (2014) comentam que essa função psíquica atua no nível inconsciente e está associada a pressentimentos, que ajudam a antecipar situações futuras.

Por fim, no modelo junguiano existem, ainda, outras duas funções psíquicas (de pensamento e de sentimento), que estão associadas às questões racionais (de julgamento). De forma resumida, Jung seguiu seus estudos com o objetivo de entender como o indivíduo toma uma decisão, que ocorre, para o autor, a partir de sua aptidão inata, conduzida pela lógica ou baseada em sentimentos.

Na função "pensamento", as pessoas julgam o objeto percebido com base em leis, critérios, classificações, normas e/ou códigos preexistentes, sem que haja excessiva interferência de valores pessoais (FIALHO; FERNANDES, 2014). Nesse caso, a avaliação é mais objetiva, pois ocorre o estabelecimento de relações conceituais. Pessoas que lidam com métodos científicos, por exemplo, fazem muito uso da função pensamento, pois trabalham com normas para a produção de conhecimento. Outro caso a ser citado são os economistas, que precisam descrever fluxos financeiros, prever tendências mercadológicas e gerir investimentos. Tudo isso é feito de maneira precisa, utilizando o raciocínio lógico.

Em contrapartida, na função "sentimento", existe maior interesse pelo julgamento de valor. De acordo com Ramos (2002), o conceito de sentimento não deve ser confundido com os conceitos afeto e emoção. Para aceitar ou rejeitar uma determinada situação, o indivíduo leva em conta valores pessoais. As decisões também são tomadas com base na identificação do outro sujeito, valorizando a empatia e a harmonia. 


\title{
2.3 A Classificação Tipológica de Myers-Briggs (MBTI)
}

Na década de 1940, a teoria dos tipos psicológicos recebeu significativas contribuições, com estudos realizados por diferentes autores. Na época, duas pesquisadoras norte-americanas, Katharine Briggs e Isabel Myers, adicionaram uma subdivisão no modelo originalmente proposto por Jung. Inicialmente, a visão geral dos tipos psicológicos era fundamentada com base em 8 tipos, definidos por disposições e funções psíquicas. Com a intervenção das pesquisadoras, foi criada a quarta função, que diz respeito à forma de se comportar, agir ou reagir do indivíduo. Nesse sentido, as pessoas podem ter uma atitude julgadora (J) ou uma atitude perceptiva (P). Sobre essa questão, Fialho e Fernandes (2014) explicam que:

\begin{abstract}
Quando se emprega uma atitude de julgamento para conduzir a vida, há uma tendência de querer que as coisas sejam elaboradas e realizadas de acordo com um planejamento inicial. Quando se emprega um processo de percepção para lidar com a vida diária, ocorre uma tendência de abertura para novas possibilidades, numa atitude de reflexibilidade na adaptação a novas circunstancias, experimentando a vida do modo mais amplo possível. (FIALHO; FERNANDES, 2014, p. 135).
\end{abstract}

Mas, como seria, de fato, as atitudes de uma pessoa julgadora (J)? Como essa pessoa conduziria sua vida? No entendimento de Navarro (2014), em geral, são pessoas com o "comportamento metódico", que preferem realizar ações de forma sistemática. Gostam da palavra previsibilidade, pois se sentem à vontade organizando tarefas. Também são compelidas a resolver problemas sempre de maneira detalhista. "A melhor forma de abordar uma pessoa tipo julgamento é apresentando métodos de trabalho, de forma breve e concisa, destacando as tarefas a serem realizadas, mostrando quais são os resultados esperados, cumprindo a agenda preestabelecida" (NAVARRO, 2014).

Em contrapartida, na função Percepção $(P)$, as pessoas preferem uma vida mais flexível (e até certo ponto "desordenada"). Diante de determinadas situações, agem como procrastinadores, pois se sentem compelidas a adiar decisões. Fazem isso com o intuito de buscar novas informações. Mesmo assim, são pessoas confortáveis diante de novos acontecimentos. Sabem lidar com isso sem a necessidade de um planejamento prévio, pois possuem forte poder de adaptação. "A melhor forma de abordar uma pessoa tipo percepção é fornecendo-Ihe sempre novas informações, estimulando sua curiosidade. Deixe-o à vontade para esclarecer todos os "por quês" que lhe vêem à mente" (NAVARRO, 2014). 
subdivisão, a classificação foi ampliada, proporcionando um total de 16 combinações distintas. No modelo MBTI (do inglês, Myers-Briggs Type Indicator), as letras são escolhidas sequencialmente, de forma a apontar o perfil comportamental de um indivíduo. Vejamos um exemplo de combinação: o código ISTJ, formado por quatro letras, indica que o indivíduo tem uma disposição Introvertida, faz uso da função Sensação para assimilar informações e recorre à função Pensamento para tomada de decisão. Além disso, adota uma conduta de Julgamento como estilo de vida.

\begin{tabular}{|c|c|c|c|}
\hline \multirow{2}{*}{$\begin{array}{l}\text { Letra } \\
1 \underline{\text { a }}\end{array}$} & \multicolumn{3}{|l|}{ SIGNIFICADO } \\
\hline & Disposição (atitudes da libido) & E - Extroversão & I - Introversão \\
\hline $2^{a}$ & Função de percepção & S - Sensação & N - Intuição \\
\hline $3^{\underline{a}}$ & Função de julgamento & $\mathrm{T}$ - Pensamento & F - Sentimento \\
\hline $4 \underline{a}$ & Forma de se comportar & J - Julgamento & P - Percepção \\
\hline
\end{tabular}

Fonte: Adaptado de Ramos (2002, p. 152)

Seguindo os princípios da Teoria dos Tipos Psicológicos, uma pessoa ISTJ pode ser descrita como tranquila e reservada, por possuir energia psíquica direcionada para o sujeito. É um indivíduo organizado e meticuloso, que geralmente consegue cumprir as atividades assumidas. Por ter a função julgamento associada à letra $T$, pode-se dizer que é pessoa que tende a confiar em leis e em tradições, e espera o mesmo das outras. Não se sente confortável infringindo regras e pode ter certa dificuldade em identificar necessidades emocionais, pelo menos da maneira com que elas são expostas. Sendo a função perceptiva de sensação (S), também é possível dizer que o indivíduo detecta os objetos de forma objetiva e concreta.

Obviamente, outras informações podem ser incorporadas na descrição anterior. Mas, de que maneira a utilização da teoria junguiana dos tipos psicológicos podeserútil para o Design? Deacordo com Fialhoe Fernandes(2014), o modelo MBTI foi amplamente difundido depois da Segunda Guerra Mundial, principalmente por aplicar a teoria à adequação profissional. Desde então, o modelo é utilizado em todo o mundo, com diversas aplicações, que vão desde o ambiente empresarial à área de comunicação, passando por testes de auxílio à escolha vocacional, planejamento de carreira, compreensão intercultural, etc.. Tais instrumentos servem, ainda, para identificar características e preferências pessoais, sendo utilizados na criação de "personas". A tabela 2, esboçada inicialmente por Hirsh e Kummerow (1995), apresenta outras características do código ISTJ, assim como dos demais tipos psicológicos: 
Quadro 2 - Características dos dezesseis tipos psicológicos.

\begin{tabular}{|c|c|c|c|}
\hline $\begin{array}{l}\text { ISTJ } \\
\text { Factuais, meticu- } \\
\text { losos, sistemáti- } \\
\text { cos, confiáveis, } \\
\text { constantes, práti- } \\
\text { cos, organizados, } \\
\text { realistas, fiéis ao } \\
\text { dever, sensatos, } \\
\text { cuidadosos. }\end{array}$ & $\begin{array}{l}\text { ISFJ } \\
\text { Detalhistas, me- } \\
\text { ticulosos, tradi- } \\
\text { cionalistas, leais, } \\
\text { pacientes, práticos, } \\
\text { organizados, volta- } \\
\text { dos para o serviço, } \\
\text { devotados, proteto- } \\
\text { res, responsáveis, } \\
\text { cuidadosos. }\end{array}$ & $\begin{array}{l}\text { INFJ } \\
\text { Compromissados, } \\
\text { leais, } \\
\text { têm grande com- } \\
\text { paixão, } \\
\text { criativos, intensos, } \\
\text { profundos, deter- } \\
\text { minados, conceitu- } \\
\text { ais, sensíveis, res- } \\
\text { ervados, globais, } \\
\text { idealistas. }\end{array}$ & $\begin{array}{l}\text { INTJ } \\
\text { Independentes, } \\
\text { lógicos } \\
\text { críticos, originais, } \\
\text { voltados para os } \\
\text { sistemas, firmes, } \\
\text { visionários, teóri- } \\
\text { cos, exigentes, } \\
\text { reservados, globais, } \\
\text { autônomos. }\end{array}$ \\
\hline $\begin{array}{l}\text { ISTP } \\
\text { Lógicos, apropri- } \\
\text { ados, } \\
\text { práticos, realistas, } \\
\text { fatuais, analíticos, } \\
\text { aplicados, inde- } \\
\text { pendentes, aven- } \\
\text { turosos, espontâ- } \\
\text { neos, adaptáveis, } \\
\text { determinados. }\end{array}$ & $\begin{array}{l}\text { ISFP } \\
\text { Atenciosos, } \\
\text { gentis, modestos, } \\
\text { adaptáveis, } \\
\text { sensíveis, obser- } \\
\text { vadores, } \\
\text { cooperativos, leais, } \\
\text { de confiança, } \\
\text { espontâneos, } \\
\text { compreensivos, } \\
\text { harmoniosos. }\end{array}$ & $\begin{array}{l}\text { INFP } \\
\text { Têm grande com- } \\
\text { paixão, gentis, vir- } \\
\text { tuosos, adaptáveis, } \\
\text { compromissados, } \\
\text { curiosos, criativos, } \\
\text { leais, devotados, } \\
\text { profundos, reser- } \\
\text { vados, enfáticos. }\end{array}$ & $\begin{array}{l}\text { INTP } \\
\text { Lógicos, céticos, } \\
\text { cognitivos, reser- } \\
\text { vados, teóricos, } \\
\text { críticos, precisos, } \\
\text { independentes, } \\
\text { especulativos, orig- } \\
\text { inais, autônomos, } \\
\text { determinados. }\end{array}$ \\
\hline $\begin{array}{l}\text { ESTP } \\
\text { Orientados } \\
\text { para atividades } \\
\text { adaptáveis, gos- } \\
\text { tam de se divertir, } \\
\text { versáteis, en- } \\
\text { ergéticos, alertas, } \\
\text { espontâneos, } \\
\text { pragmáticos, } \\
\text { despreocupados, } \\
\text { rápidos, persua- } \\
\text { sivos, amigáveis. }\end{array}$ & $\begin{array}{l}\text { ESFP } \\
\text { Entusiasmados, } \\
\text { adaptáveis, diver- } \\
\text { tidos, amigáveis, } \\
\text { alegres, sociáveis, } \\
\text { comunicativos, } \\
\text { cooperativos, de- } \\
\text { spreocupados, tol- } \\
\text { erantes, agradáveis. }\end{array}$ & $\begin{array}{l}\text { ENFP } \\
\text { Criativos, curiosos, } \\
\text { entusiasmados, } \\
\text { versáteis, espontâ- } \\
\text { neos, expressivos, } \\
\text { independentes, } \\
\text { amigáveis, percep- } \\
\text { tivos, energéticos, } \\
\text { imaginativos, } \\
\text { incansáveis. }\end{array}$ & $\begin{array}{l}\text { ENTP } \\
\text { Empreendedores, } \\
\text { independentes, sin- } \\
\text { ceros, estratégicos, } \\
\text { criativos, adaptáveis, } \\
\text { desafiadores, analíti- } \\
\text { cos, inteligentes, } \\
\text { engenhosos, ques- } \\
\text { tionadores, teóricos. }\end{array}$ \\
\hline $\begin{array}{l}\text { ESTJ } \\
\text { Lógicos, decidi- } \\
\text { dos, sistemáticos, } \\
\text { objetivos, eficien- } \\
\text { tes, diretos, práti- } \\
\text { cos, organizados, } \\
\text { impessoais, } \\
\text { responsáveis, } \\
\text { estruturados, } \\
\text { cuidadosos. }\end{array}$ & $\begin{array}{l}\text { ESFJ } \\
\text { Cuidadosos, } \\
\text { leais, sociáveis, } \\
\text { agradáveis, } \\
\text { responsáveis, } \\
\text { harmoniosos, } \\
\text { cooperativos, } \\
\text { diplomáticos, me- } \\
\text { ticulosos, prestati- } \\
\text { vos, complacentes, } \\
\text { tradicionais. }\end{array}$ & $\begin{array}{l}\text { ENFJ } \\
\text { Leais, idealistas, } \\
\text { agradáveis, ver- } \\
\text { bais, responsáveis, } \\
\text { expressivos, } \\
\text { entusiasmados, } \\
\text { energéticos, } \\
\text { diplomáticos, } \\
\text { preocupados, } \\
\text { prestativos, } \\
\text { amigáveis. }\end{array}$ & $\begin{array}{l}\text { ENTJ } \\
\text { Lógicos, decisivos, } \\
\text { planejadores, duros, } \\
\text { estratégicos, críti- } \\
\text { cos, controlados, } \\
\text { desafiadores, dire- } \\
\text { tos, objetivos, justos, } \\
\text { teóricos. }\end{array}$ \\
\hline
\end{tabular}

Fonte: Hirsh e Kummerow (1995, p. 14).

\section{Conceito de Persona}

No livro Tipos Psicológicos, Jung apresenta a definição de "persona". O termo, de origem latina, faz referência às máscaras utilizadas pelos atores do teatro grego, que davam significado aos papéis representados. Para Jung 
(2000), ao colocar uma máscara, sabe-se claramente o que ela corresponde: "por uma parte, a seus propósitos e, por outra parte, às exigências e opiniões dos que o cercam [...]. A essa máscara, adotada ad hoc, dei o nome de persona $[\ldots]^{\prime \prime}(J U N G, 2000$, p. 478).

Nesse sentido, para a Psicologia Analítica, o termo é compreendido, então, como um arquétipo, pois está associado ao comportamento do indivíduo frente ao mundo exterior ${ }^{4}$. Esse comportamento indica a maneira na qual cada sujeito se mostra, isto é, o caráter assumido, necessário para sua adaptação às exigências do meio social.

Sobre essa questão, Stein (1998, p. 102) acresce a citação de Jung, dizendo que, "hoje, o termo "persona é aceito no vocabulário da psicologia e da cultura contemporânea. É usado com frequência na linguagem popular, nos jornais e na teoria literária". Significa a pessoa tal como é apresentada, não a pessoa como realmente é.

De forma análoga, no campo do Design, o termo indica uma imagem fictícia do público-alvo. Em outras palavras, "persona" é uma ferramenta de projeto, utilizada para entendimento profundo das preferências do consumidor. Na visão de Pazmino (2015, p. 108), "pessoas imaginárias - personas - podem ajudar o designer no desenvolvimento de produtos, principalmente para enxergar o que o público gostaria de usar". Para fazer uso da ferramenta, continua a autora, criase uma descrição detalhada desse público. Logo, os modelos representativos ganham, de imediato, nome, endereço, profissão e personalidade, fazendo com que haja clareza dos anseios indicados.

Tal descrição deve ser feita a partir de diversos aspectos, incluindo a aparência física, a função ou o papel social, os estados emocionais e as características inatas/permanentes. "O designer, quando trabalha apenas com uma descrição técnica do público-alvo, esta é impessoal e superficial. Contudo, quando é criada a 'persona', existe um olhar diferente para o público" [...] (PAZMINO, 2015, p. 109).

Esse olhar diferente, apontado no texto de Pazmino (2015), pode ser melhor compreendido quando se apresentam algumas características pontuais de uso da ferramenta. Existe, por exemplo, diferenças substanciais na criação de personas para as áreas de Marketing e Design. Quando se trabalha com

$4 \quad 0$ uso de "máscaras", para desempenhar papéis sociais, justifica-se de duas formas: a primeira diz respeito à necessidade de proteção (contra a intrusão do mundo exterior). A segunda refere-se à própria adaptação do indivíduo, que deve se comportar adequadamente perante aos costumes sociais do grupo. Sobre essa questão, Stein (1998) sugere que o uso de máscaras não transforma o indivíduo em personagens individuais, mas sim, em representações coletivas. 
desenvolvimento de produto, a descrição deve envolver situações de uso do artefato (PRUITT; ADLIN, 2006). Todo artefato tem, pelo menos, uma finalidade de uso. Nesse sentido, devem-se relatar possíveis problemas, ligados às dificuldades enfrentadas pelo usuário na utilização adequada do objeto.

Personas ajudam nas principais atividades de Marketing. Ajudam na formulação de estratégias para posicionamento de produtos e no planejamento/execução dos meios de comunicação, tais como: uso de catálogos, conteúdos da Web e anúncios. O principal objetivo de uma persona na área de Marketing é compreender os fatores que influenciam as pessoas no momento de compra. Assim, a principal diferença entre o uso de personas no Marketing e no Design está no foco de suas histórias. No Marketing, a persona conta a história de alguém que vai realizar a compra, ao passo que, no Design, ela conta a história de alguém que realmente fará uso do objeto. Em outras palavras, essa é a diferença entre um cliente e um usuário (PRUITT; ADLIN, 2006, p. 617, tradução nossa).

Relatando as dificuldades encontradas no uso do objeto, o profissional tende a se "aproximar" da realidade projetual, podendo, assim, enxergar características requeridas para o produto em um contexto de uso específico.

\section{Definindo os Tipos Psicológicos}

Uma vez compreendido o conceito de "persona", o próximo passo passa a ser a aplicação do modelo. Sobre esta questão, existe a recomendação que:

Na tentativa de entender melhor o nosso comportamento, assim como o de nossos semelhantes, começamos a classificar as pessoas, de acordo com suas semelhanças e diferenças, originando, assim, os sistemas tipológicos [...]. Quando os sistemas tipológicos estudam os temperamentos das pessoas, temos os tipos psicológicos, que representam maneiras pelas quais as pessoas selecionam e organizam as informações que recebem do ambiente externo, formam suas ideais e tomam decisões. Os tipos, assim, caracterizam as pessoas quanto a interesses, preferências e habilidades (FIALHO; FERNANDES, 2014, p. 17). 
indicam o uso de testes. No Brasil, existem sites gratuitos, que permitem maior reflexão sobre o tema. Um desses sites é o "http://inspiira.org/", que busca disseminar conhecimentos sobre as preferências do indivíduo. Nesse ponto, é prudente destacar que não se trata de um simples teste de personalidade. $O$ instrumento foi criado para "verificar" padrões de resposta comportamental, inferindo estruturas ou perfis de temperamento inato.

Em inglês, outra opção de consulta é o site "http://www.keirsey.com/", que já apresenta em sua estrutura o modelo dos quatro temperamentos. $\mathrm{O}$ teste também é conduzido por meio de um questionário, com perguntas que descrevem situações e preferências. Da mesma forma que o exemplo anterior, utiliza como referência os dezesseis tipos psicológicos de Katharine Briggs e Isabel Myers.

Ambos os testes servem para possibilitar o conhecimento de necessidades coletivas. Os testes fornecem informações cruciais, fornecendo descrições que identificam arquétipos e representam parte de um grupo. No entanto, isso só não basta para a definição de persona. No caso do Design, para apresentar o público-alvo, é comum que se faça uso de narrativas, que criam uma sequência interligada de fatos. As narrativas também podem ser construídas a partir de resultados de pesquisas, fruto de entrevistas, questionários e dados observados em campo (PAZMINO, 2015).

Como resultado da técnica, descreve-se o perfil de uma pessoa com o máximo de detalhes. Nesse sentido, não devem ser descritos, somente, o nome, a idade, o sexo, a família, o endereço, o emprego e as características físicas. Como observado no decorrer do texto, mais importante que isso, são os aspectos relacionados às preferências de uso, aos hábitos, às dificuldades enfrentadas e aos temperamentos do usuário (que vão influenciar, diretamente, a relação do mesmo com o objeto).

\section{CONCLUSÃO}

Discutida em forma de artigo, a revisão bibliográfica é, obviamente, um pequeno recorte frente à importância do tema. Dentro da literatura referenciada existem apontadores para um campo mais vasto de pesquisa. No entanto, dando "voz" a Carl Jung, foi possível perceber a correlação existente entre as áreas de Psicologia Analítica e Design, sobretudo por meio da Teoria dos Tipos Psicológicos.

Antes de explorar a classificação tipológica de Myers-Briggs, foi feita uma breve revisão do modelo psíquico concebido por Jung. O modelo foi apresentado, inicialmente, para compreensão da noção de arquétipo, responsável por gerar padrões de comportamento. Um padrão de comportamento é uma maneira de 
agir, que sempre se repete diante de situações parecidas. Como observou Jung (2000), em todas as culturas aparecem determinados elementos formais que se replicam. Isso ocorre nos mais variados indivíduos.

Portanto, no entendimento da psicologia junguiana, as pessoas possuem "comportamentos universais". Nesse sentido, compreender essa realidade pode ser oportuno para o designer, que geralmente cria modelos representativos (personas) para explicar as mais variadas condutas preferidas pelo públicoalvo. Esses modelos representativos de público não precisam ser feitos de forma intuitiva, já que existe base teórica para fundamentar o pensamento. Não se trata de "rotular pessoas", como salientou o próprio Jung quando definiu os tipos psicológicos. A proposta é identificar temperamentos e características comuns, de origens psíquica e biológica.

No caso do Design, antes de gerar os esboços iniciais para concepção do objeto, usualmente se define o público-alvo, responsável por usar ou consumir o produto. Sendo assim, as portas se abrem para o uso de uma série de testes que permitem determinar, com maior precisão, os tipos psicológicos das pessoas. Vale lembrar que a seleção dos testes e a interpretação dos resultados requerem conhecimento específico, uma vez que o objetivo principal dos mesmos é contribuir para a compreensão do indivíduo. Design, na atualidade, é tarefa que exige mais interdisciplinaridade com a co-criação substituindo a criação. A compreensão dos tipos nos permite ampliar esse diálogo e entender os diferentes pontos de vista.

\section{REFERÊNCIAS}

CYBIS, W.; BETIOL, A.; FAUST, R. Ergonomia e usabilidade:

conhecimentos, métodos e aplicações. 2. ed. São Paulo: Novatec, 2010.

FIALHO, F. A.; FERNANDES, E. G. Tipologias e arquétipos: a psicologia profunda com base para uma hermenêutica. Florianópolis: Insular, 2014.

HIRSH, S. K.; KUMMEROW, J. M. Introdução aos tipos psicológicos nas organizações. São Paulo: Coaching Consultoria Estratégica, 1995.

JUNG, C. G. Os arquétipos e o inconsciente coletivo. Petrópolis: Vozes, 2000.

Tipos psicológicos. Petrópolis: Vozes, 1991. Originalmente publicado em 1920. 
PAZMINO, A. V. Como se cria: 40 métodos para design de produtos. São Paulo: Blucher, 2015.

PRUITT, J.; ADLIN, T. The Persona lifecycle: keeping people in mind throughout product design. San Francisco: Morgan Kaufmann, 2006.

RAMOS, L. M. A. Apontamentos sobre a psicologia analítica de Carl Gustav Jung. Educação Temática Digital, Campinas, v. 4, n. 1, p. 110143, dez. 2002.

STEIN, M. Jung's map of the soul: an introduction. Chicago: Open Court Publishing Company, 1998. 


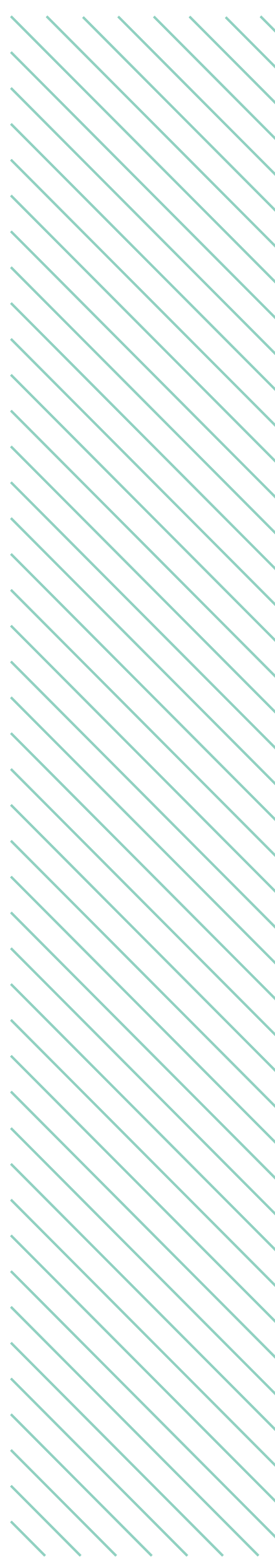

